\title{
Isotope Effect in the Activation of a Mechanophore
}

DOI:

10.1021/jacs.0c11259

\section{Document Version}

Accepted author manuscript

Link to publication record in Manchester Research Explorer

\section{Citation for published version (APA):}

Nixon, R., \& De Bo, G. (2020). Isotope Effect in the Activation of a Mechanophore. J. Am. Chem. Soc. https://doi.org/10.1021/jacs.0c11259

\section{Published in:}

J. Am. Chem. Soc.

\section{Citing this paper}

Please note that where the full-text provided on Manchester Research Explorer is the Author Accepted Manuscript or Proof version this may differ from the final Published version. If citing, it is advised that you check and use the publisher's definitive version.

\section{General rights}

Copyright and moral rights for the publications made accessible in the Research Explorer are retained by the authors and/or other copyright owners and it is a condition of accessing publications that users recognise and abide by the legal requirements associated with these rights.

\section{Takedown policy}

If you believe that this document breaches copyright please refer to the University of Manchester's Takedown Procedures [http://man.ac.uk/04Y6Bo] or contact uml.scholarlycommunications@manchester.ac.uk providing relevant details, so we can investigate your claim.

\section{OPEN ACCESS}




\title{
Isotope Effect in the Activation of a Mechanophore
}

\author{
Robert Nixon and Guillaume De Bo* \\ Department of Chemistry, University of Manchester, Oxford Road, Manchester, M13 9PL, United Kingdom
}

Supporting Information Placeholder

\begin{abstract}
In mechanochemistry, molecules under tension can react in unexpected ways. The reactivity of mechanophores (mechanosensitive molecules) can be controlled using various geometric or electronic factors. Often these factors affect the rate of mechanical activation but sometimes give rise to alternative reaction pathways. Here we show that a simple isotope substitution $(\mathrm{H}$ to D) leads to a reversal of selectivity in the activation of a mechanophore. Remarkably this isotope effect is not kinetic in nature but emerges from dynamic effects in which deuteration reduces the ability of the reactant to follow a post-transition-state concerted trajectory on the bifurcated force-modified potential energy surface. These results give a new insight into the reactivity of molecules under tension.
\end{abstract}

The reactivity of molecules under tension can significantly deviate from their force-free reactivity. ${ }^{1,2}$ Since the emergence of the mechanophore concept, ${ }^{3}$ chemists have been able to explore and control reactivity under tension with clever molecular designs. ${ }^{4}$ Several factors affecting the reactivity under tension have been uncovered such as: the polymer architecture, ${ }^{5-7}$ the nature of the linker, ${ }^{8-12}$ substituents, ${ }^{13-16}$ or dependence on their stereo-, ${ }^{16-22}$ regio-, ${ }^{18,23-27}$ or topochemistry. ${ }^{28-30}$ These factors usually affect the rate of activation or, more rarely, the outcome of the reaction itself. ${ }^{13,21,31,32}$ The latter case often being the result of a post-transition-state bifurcation on the force modified potential energy surface (PES). ${ }^{13,32,33}$

We have recently shown that the mechanical activation of $\mathbf{1}_{\mathbf{H}}$ proceeds via three concomitant dissociation pathways: homolytic, heterolytic, and concerted. ${ }^{13}$ Interestingly, the polarization of the scissile bond (i.e. the number of $\mathrm{F}$ atoms $\left(n_{F}\right)$ in the aromatic leaving group) dictates the major pathway: high polarization $\left(n_{F}=4, \mathbf{1}_{\mathbf{H}} \mathbf{a}\right)$ favors a heterolytic scission, while a less polarized bond leads to the predominant formation of a carbene via a concerted mecha$\operatorname{nism}\left(n_{F}=1, \mathbf{1}_{\mathbf{H}} \mathbf{c}\right)$. We found that the coexistence of these dissociation pathways was due to a post-transition state bifurcation on the force-modified potential energy surface. Here we investigate the influence of hydrogen isotopes on the activation of a mechanophore. We found that the replacement of the imidazolidine $\mathrm{H}$ by a $\mathrm{D}$ atom (noted $\mathrm{X}$ in $\mathbf{1} \mathbf{x}$, Scheme 1) favors the heterolytic scission over the concerted pathway. This isotope effect culminates in the less polarized mono-fluoro adduct where a complete reversal of selectivity is observed. This effect is the result of the dynamic behavior of the reactant, in which the smaller stretching frequency and amplitude of the C-D bond reduces the ability of the reactant to follow a concerted trajectory. These results provide a new way to control reactivity of molecules under tension and could lead to the expansion of the reactive space of known mechanophores and provide a blueprint for the design of new ones.

Scheme 1. Mechanical activation of protonated $\left(1_{\mathrm{Ha}} \mathrm{a}\right.$ c) and deuterated (1, a-c) imidazolidine mechanophores*

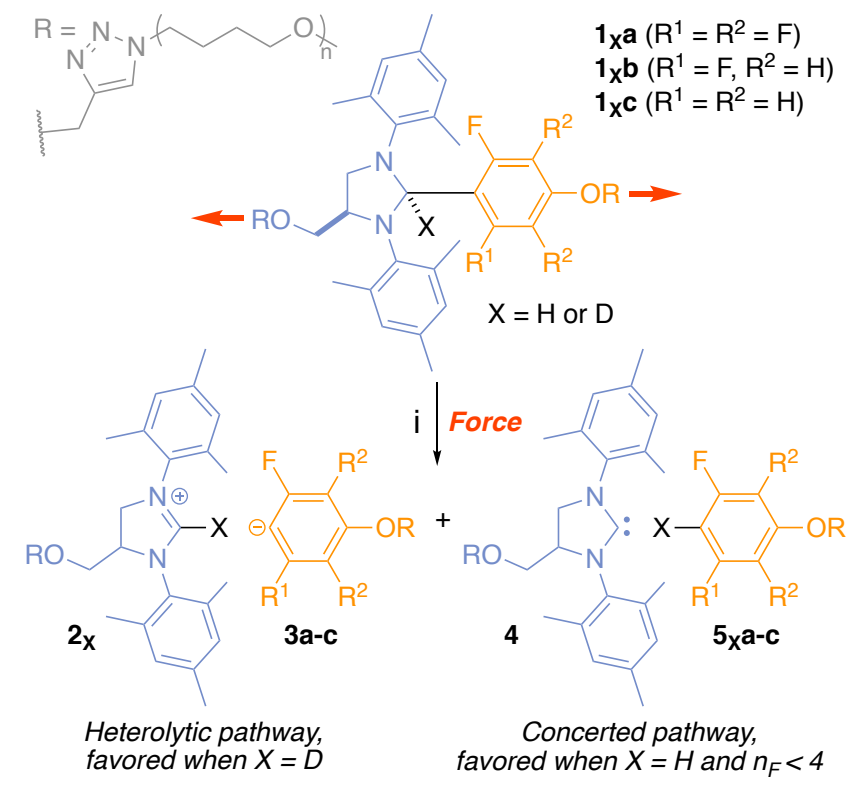

*Conditions: (i) US (20 kHz, $15.6 \mathrm{~W} / \mathrm{cm}^{2}, 1 \mathrm{~s}$ ON/ $\left.1 \mathrm{~s} \mathrm{OFF}\right)$, $\mathrm{THF} / \mathrm{H}_{2} \mathrm{O}$ (with $\mathbf{1}_{\mathbf{D}} \mathbf{a}-\mathbf{c}$ ) or THF/ $\mathrm{D}_{2} \mathrm{O}$ (with $\mathbf{1}_{\mathbf{H}} \mathbf{a}-\mathbf{c}$ ), $5-10{ }^{\circ} \mathrm{C}$, $180 \mathrm{~min}$. Minor homolytic pathway not shown. Red arrows indicate the direction of the force. 
We performed the mechanical activation of adducts $1 \times \mathbf{x}$ a-c in $\mathrm{THF} / \mathrm{H}_{2} \mathrm{O}\left(\mathbf{1}_{\mathbf{D}} \mathbf{a}-\mathbf{c}\right)$ or $\mathrm{THF} / \mathrm{D}_{2} \mathrm{O}\left(\mathbf{1}_{\mathbf{H}} \mathbf{a}-\mathbf{c}\right)$ at $5-10{ }^{\circ} \mathrm{C}$, using high-intensity ultrasound (Scheme 1). In the concerted pathway, the imidazolidine H(D) migrates to the aryl leaving group during the scission event to form $\mathbf{5}_{\mathbf{X}}$, while aryl anion 3 is generated by heterolytic cleavage. This anion is then trapped by $\mathrm{H}_{2} \mathrm{O}$ (when $\mathrm{X}=\mathrm{D}$ ), or $\mathrm{D}_{2} \mathrm{O}$ (when $\mathrm{X}=\mathrm{H}$ ) to differentiate it from the product of the concerted pathway (Figure 1a). Compounds $\mathbf{5}_{\mathbf{D}}$ and $\mathbf{5}_{\mathbf{H}}$ can be distinguished by ${ }^{19} \mathrm{~F}$ NMR due to the slight difference in chemical shift of $\mathrm{F}$ atoms when they are adjacent to $\mathrm{H}$ or $\mathrm{D}$ (Figure 1b-d). As an example, the sonication of $\mathbf{1}_{\mathbf{D}} \mathbf{b}$ in $\mathrm{THF} / \mathrm{H}_{2} \mathrm{O}$ (Figure 1a), furnishes $\mathbf{5}_{\mathbf{H}} \mathbf{b} / \mathbf{5}_{\mathbf{D}} \mathbf{b}$ in a $74 / 26$ ratio (Table 1) as determined by the integration of the corresponding peaks (-108.96 ppm for $\mathbf{5}_{\mathbf{H}} \mathbf{b}$ and $-109.24 \mathrm{ppm}$ for $5 \mathrm{Db}$ ) in the post-sonication ${ }^{19} \mathrm{~F}$ NMR spectrum (Figure 1c). The importance of the concerted and heterolytic pathways for the other mechanophore were determined in the same way (see SI) and are reported in Table 1. a

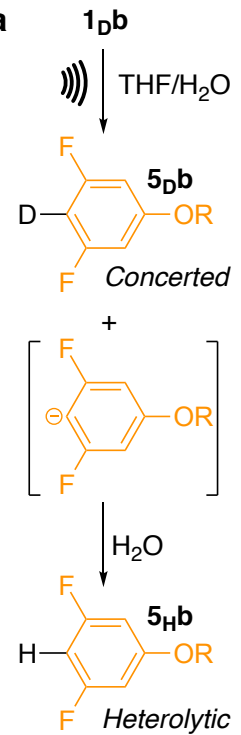

b

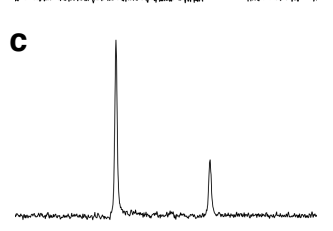

d

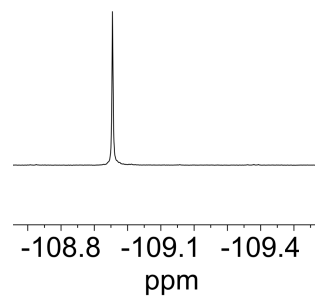

Figure 1. Determination of the relative importance of the concerted and heterolytic pathways by ${ }^{19} \mathrm{~F}$ NMR. (a) Mechanical activation of deuterated difluoro-derivative 1Db produces deuterated difluoro aryl $\mathbf{5} \mathbf{D b}$, via a concerted pathway, and the corresponding anion by heterolytic scission. Protonation of the latter by $\mathrm{H}_{2} \mathrm{O}$ furnishes $\mathbf{5}_{\mathbf{H}} \mathbf{b}$. The ratio $\mathbf{5} \mathbf{D b} / \mathbf{5} \mathbf{H b}$ is determined by ${ }^{19} \mathrm{~F}$ NMR (partial spectra, 376 $\mathrm{MHz}, \mathrm{C}_{6} \mathrm{D}_{6}$ ): (b) sonication of $\mathbf{1}_{\mathbf{D}} \mathbf{b}$ in presence of $\mathrm{D}_{2} \mathrm{O}$, (c) sonication of $1 \mathbf{D b}$ in presence of $\mathrm{H}_{2} \mathrm{O}$, (d) $5 \mathrm{Hb}$ reference compound.

Two trends emerge from these results (Table 1): the proportion of concerted dissociation increases as the polarization of the scissile bond increases in the protonated series $\left(1_{\mathbf{H}} \mathbf{a}-\mathbf{c}\right),{ }^{13}$ while the heterolytic scission is always favored in the deuterated series $\left(\mathbf{1}_{\mathbf{D}} \mathbf{a}-\mathbf{c}\right)$. This latter trend culminates with the mono-fluoro adduct, which displays an almost complete reversal of selectivity upon deuteration. ${ }^{34}$ We have previously shown that the mechanistic divergence was the result of a post-transition-state bifurcation on the force-modified potential energy surface (PES). ${ }^{13}$ Upon activation of the mechanophore, the $\mathrm{C}_{1}-\mathrm{C}_{2}$ bond connecting the aromatic leaving group to the imidazolidine unit elongates until it reaches the transition state (TS, Figure 2a). Further elongation of this bond leads to the heterolytic cleavage of the mechanophore to produce an imidazolinium cation and an aryl anion $\left(\mathbf{P}_{\text {hetero }}\right)$ while concomitant elongation of $\mathrm{C}_{1}-\mathrm{H}$ and $\mathrm{C}_{1}-\mathrm{C}_{2}$ brings the reactive intermediate onto a concerted trajectory that ultimately delivers a carbene and a neutral aromatic unit $\left(\mathbf{P}_{\text {conc }}\right)$. This divergence is specific to the mechanical activation; the reaction proceeds exclusively via a concerted pathway at zero-force.

Table 1. Distribution of mechanical scission products in function of the substitution ${ }^{\mathrm{a}}$

\begin{tabular}{|l|l|l|l|l|l|}
\hline $\begin{array}{l}\text { Ad- } \\
\text { duct }\end{array}$ & $n_{F}$ & $X$ & $\begin{array}{l}\text { Heterolytic } \\
(\%)\end{array}$ & $\begin{array}{l}\text { Con- } \\
\text { certed } \\
(\%)\end{array}$ & $\begin{array}{l}\text { Homolytic } \\
(\%)\end{array}$ \\
\hline \multirow{2}{*}{$\boldsymbol{1}_{\boldsymbol{X}} \boldsymbol{a}$} & 4 & $H$ & 68 & 27 & 5 \\
\cline { 2 - 6 } & $D$ & 70 & 24 & 6 \\
\hline \multirow{2}{*}{$\boldsymbol{1}_{\boldsymbol{X}} \boldsymbol{b}$} & 2 & $H$ & 45 & 55 & n.o. \\
\cline { 2 - 6 } & \multirow{2}{*}{$\boldsymbol{1}_{\boldsymbol{X} \boldsymbol{c}}$} & $\mathrm{D}$ & 71 & 26 & 3 \\
\cline { 2 - 6 } & & $D$ & 25 & 75 & n.o. \\
\hline
\end{tabular}

${ }^{\mathrm{a}}$ n.o. $=$ not observed. Error: $\pm 1 \%$.

We calculated the force-modified PES (DFT B3LYP/6$31 \mathrm{G}^{*}$, solvent model: SM8=THF) for short models $(\mathbf{R}$, Figure 2a) of the tetra- (Figure 2b), di- (Figure 2c), and mono-fluoro (Figure 2d) mechanophores $\mathbf{1}_{\mathbf{H}} \mathbf{a - c}$. The distance between the terminal Me groups was set at $13.839 \AA$ to mimic the highest energy structures $\left(E_{\max }\right)$ observed in the CoGEF calculations (see SI). Force-modified PES of the tetra-fluoro mechanophore (Figure $2 b$ ) shows two distinctive valleys associated with the two concurrent dissociation pathways in the post-transition state region of the PES. As the polarization of the scissile bond decreases, the energy of the heterolytic trajectory increases due to a diminishing ability of the aromatic leaving group to stabilize the developing negative charge (Figure 2c-d). This phenomenon explains the reactivity observed in the protonated series $(\mathrm{X}=\mathrm{H}$, Table 1), but doesn't account for the change in selectivity observed in the deuterated series. For these compounds, the proportion of heterolytic pathway is relatively insensitive to the polarization of the scissile bond (Table 1), although the selectivity reversal is more pronounced in the mono-fluoro mechanophore $1 \mathbf{x} c$ than in the tetra-fluoro $\mathbf{1} \mathbf{x} \mathbf{a}$ where the selectivity remains unchanged. This effect is unlikely to originate from an ordinary kinetic isotope effect, because the $\mathrm{C}^{1}-\mathrm{H}$ bond is almost unchanged between $\mathbf{R}$ and $\mathbf{T S} .{ }^{13}$ Since the product distribution is the result of a post-transition-state 
bifurcation, the isotope effect must arise from the dynamic behavior of the reactant that produces a change in the preferred reaction trajectory.

The trajectory leading to the heterolytic products can be reduced to a single coordinate along the $\mathrm{C}^{1}-\mathrm{C}^{2}$ elongation axis, while the trajectory leading to the concerted products progresses along both the $\mathrm{C}^{1}-\mathrm{C}^{2}$ and $\mathrm{C}^{1}-\mathrm{H}$ axis. The bifurcation between the two occurs in the 'selection area', a region of the PES surrounding the valley-ridge inflexion (VRI) point (e.g. boxed region in Figure $2 \mathrm{~d}$ for $n_{F}=1$ ). This transition is accompanied by a change in the curvature of the PES, from negative around the TS to positive around the VRI (Figure 2e). In our system, this change is marked by the reduction of the $\mathrm{C}^{2}-\mathrm{C}^{1}-\mathrm{H}$ angle (see SI) to the extent that these three atoms become co-linear (Figure 2a). Past the VRI, the reactant 'commits' to a reaction pathway. The concerted trajectory presents a steeper profile but requires greater atom motion. Hence, one might intuitively imagine that the heavier isotope should follow the least dynamic trajectory (the heterolytic pathway here). In fact, the probability of following one trajectory over the other will depend on the capacity of the reactant to explore the 'selection area'. Since the two trajectories differ by the extent of the $\mathrm{C}$-X elongation, the selection will be dictated by the stretching of the $\mathrm{C}-\mathrm{X}$ bond.
Namely, the amplitude and/or the frequency of the C-X bond stretching vibration.

We calculated (DFT B3LYP/6-31G*, solvent model: $\mathrm{SM} 8=\mathrm{THF}$ ) the stretching frequencies of the $\mathrm{C}-\mathrm{X}$ bond for the various models $\left(n_{F}=1,2,4 ; \mathrm{C}^{1}-\mathrm{H}=1.09 \AA\right)$ along the heterolytic pathway, and determined the stretching amplitude from there (see SI). Due to the heavier D atom, both the stretching amplitude and frequency found for the C-D bond were smaller than for the $\mathrm{C}-\mathrm{H}$ bond. In the monofluoro adduct for instance, we found a large difference in frequencies $\left(v_{\mathrm{H}}=89 \mathrm{THz}, v_{\mathrm{D}}=66 \mathrm{THz}\right.$; average over $\mathrm{C}^{1}$ $\left.\mathrm{C}^{2}=[2.205-2.505]\right)$ but a relatively small difference in amplitude $\left(\mathrm{x}_{\mathrm{H}}=0.0384 \AA, \mathrm{x}_{\mathrm{D}}=0.0367 \AA\right)$. Nevertheless, a closer look at the selection area (Figure 2e) of the PES of this adduct reveals that even minute changes in amplitude could drive the reaction toward the concerted pathway. This effect is amplified by the higher stretching frequency of the $\mathrm{C}-\mathrm{H}$ bond: both the amplitude and the frequency act in synergy to increase the probability of bifurcation over the duration of the scission event. Remarkably, this dynamic isotope effect is able to overcome the influence of fluorination on the selectivity since the proportion of heterolytic pathway is relatively insensitive to the polarization of the scissile bond in the deuterated series (Table 1).

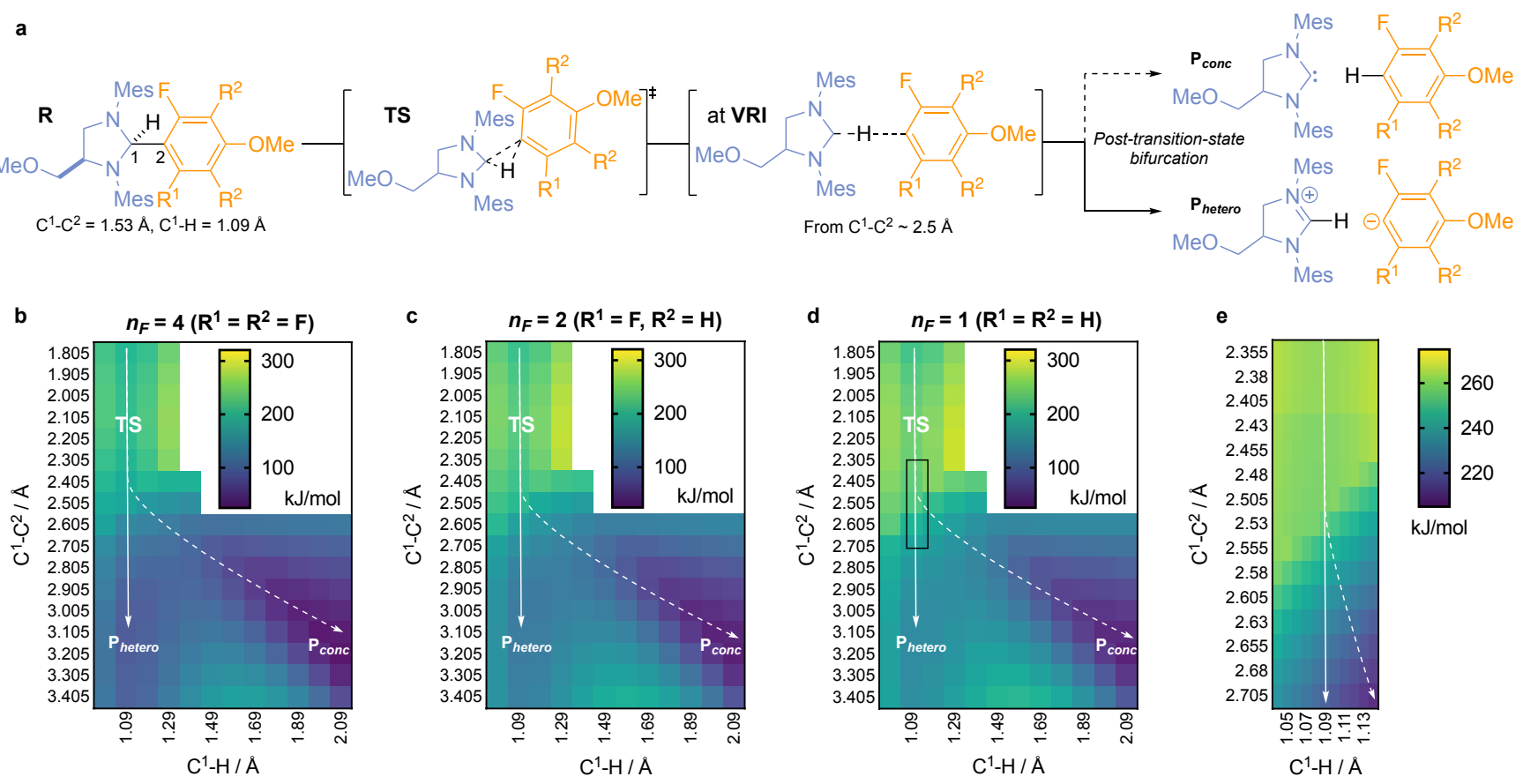

Figure 2. Origin of the isotope effect in the post-transition-state bifurcation on the force-modified potential energy surface. (a) Proposed mechanism for the mechanical cleavage of $\mathrm{C}_{1}-\mathrm{C}_{2}$ bond leading to concerted and heterolytic products. PES (B3LYP/6$31 \mathrm{G}^{*} / \mathrm{SM} 8=\mathrm{THF}$ ) for the dissociation of $\mathrm{C}_{1}-\mathrm{C}_{2}$ in R where $n_{F}=4(\mathrm{~b}), n_{F}=2(\mathrm{c})$, and $n_{F}=1$ (d) at a constrained Me-Me distance of $13.839 \AA\left(F_{\max }\right)$. The relative energy of each intermediate was determined by setting the energy of the force-free state $(R)$ at $0 \mathrm{~kJ} / \mathrm{mol}$. Plain and dashed lines indicate heterolytic and concerted pathways respectively. The energy values associated with the heterolytic pathway are probably overestimated because the solvent model used in the calculation (SM8=THF) is less polar than the solvent mixture used in the sonication experiments $\left(\mathrm{THF} / \mathrm{D}_{2} \mathrm{O}\right)$. (e) Zoom on the 'selection area' (black box in d) for $n_{F}=1\left(\mathrm{~B} 3 \mathrm{LYP} / 6-31 \mathrm{G}^{*}\right)$. The energy values associated with the heterolytic pathway are probably overestimated due to the lack of a solvent model. 
In conclusion, we have uncovered a dynamic isotope effect in the activation of a mechanophore. This effect likely emerges from the smaller stretching frequency and amplitude of the C-D bond, which reduces the ability of the reactant to follow a concerted trajectory in favor of the heterolytic pathway. Our results present a new insight into the remarkable behavior of molecules under tension and show how small changes in their dynamic properties can lead to large changes in reactivity. With this particular mechanophore, the fine tuning of electronic and isotope effects allowed us to selectively form the N-heterocyclic carbene product, or any of the aryl anion of varied basicity. Overall, this addition to the mechanochemistry toolbox should provide exciting opportunities to expand the reactive space of known mechanophores and design new ones.

\section{ASSOCIATED CONTENT}

\section{Supporting Information}

Detailed descriptions of CoGEF calculations, synthetic procedures, characterization of new compounds, and spectroscopic data. This material is available free of charge via the Internet at http://pubs.acs.org.

\section{AUTHOR INFORMATION}

\section{Corresponding Author}

*guillaume.debo@manchester.ac.uk

\section{ACKNOWLEDGMENT}

We thank the EPSRC for a studentship (to R.N.). G.D.B. is a Royal Society University Research Fellow.

\section{REFERENCES}

(1) Caruso, M. M.; Davis, D. A.; Shen, Q.; Odom, S. A.; Sottos, N. R.; White, S. R.; Moore, J. S. Mechanically-Induced Chemical Changes in Polymeric Materials. Chem. Rev. 2009, 109 (11), 57555798 .

(2) Beyer, M. K.; Clausen-Schaumann, H. Mechanochemistry: the Mechanical Activation of Covalent Bonds. Chem. Rev. 2005, 105 (8), 2921-2948.

(3) De Bo, G. Polymer Mechanochemistry and the Emergence of the Mechanophore Concept. Macromolecules 2020, 53 (18), 76157617.

(4) Klein, I. M.; Husic, C. C.; Kovács, D. P.; Choquette, N. J.; Robb, M. J. Validation of the CoGEF Method as a Predictive Tool for Polymer Mechanochemistry. J. Am. Chem. Soc. 2020, 142 (38), 16364 16381.

(5) Peterson, G. I.; Lee, J.; Choi, T.-L. Multimechanophore Graft Polymers: Mechanochemical Reactions at Backbone-Arm Junctions. Macromolecules 2019, 52 (24), 9561-9568.

(6) Lin, Y.; Zhang, Y.; Wang, Z.; Craig, S. L. Dynamic Memory Effects in the Mechanochemistry of Cyclic Polymers. J. Am. Chem. Soc. 2019, 141 (28), 10943-10947.

(7) Church, D. C.; Peterson, G. I.; Boydston, A. J. Comparison of Mechanochemical Chain Scission Rates for Linear Versus ThreeArm Star Polymers in Strong Acoustic Fields. ACS Macro Lett. 2014, 648-651.

(8) Stevenson, R.; Zhang, M.; De Bo, G. Mechanical Activation of Polymers Containing Two Adjacent Mechanophores. Polym. Chem. 2020, 11 (16), 2864-2868.
(9) Wang, J.; Kouznetsova, T. B.; Kean, Z. S.; Fan, L.; Mar, B. D.; Martinez, T. J.; Craig, S. L. A Remote Stereochemical Lever Arm Effect in Polymer Mechanochemistry. J. Am. Chem. Soc. 2014, 136 (43), 15162-15165.

(10) Klukovich, H. M.; Kouznetsova, T. B.; Kean, Z. S.; Lenhardt, J. M.; Craig, S. L. A Backbone Lever-Arm Effect Enhances Polymer Mechanochemistry. Nat. Chem. 2013, 5 (2), 110-114.

(11) Tian, Y.; Boulatov, R. Quantum-Chemical Validation of the Local Assumption of Chemomechanics for a Unimolecular Reaction. ChemPhysChem 2012, 13 (9), 2277-2281.

(12) Klukovich, H. M.; Kean, Z. S.; Ramirez, A. L. B.; Lenhardt, J. M.; Lin, J.; Hu, X.; Craig, S. L. Tension Trapping of Carbonyl Ylides Facilitated by a Change in Polymer Backbone. J. Am. Chem. Soc. 2012, 134 (23), 9577-9580.

(13) Nixon, R.; De Bo, G. Three Concomitant C-C Dissociation Pathways During the Mechanical Activation of an N-Heterocyclic Carbene Precursor. Nat. Chem. 2020, 12 (9), 826-831.

(14) Lin, Y.; Craig, S. L. Oxidative Regulation of the Mechanical Strength of a C-S Bond. Chem. Sci. 2020, 11, 10444-10448.

(15) Barbee, M. H.; Kouznetsova, T.; Barrett, S. L.; Gossweiler, G. R.; Lin, Y.; Rastogi, S. K.; Brittain, W. J.; Craig, S. L. Substituent Effects and Mechanism in a Mechanochemical Reaction. J. Am. Chem. Soc. 2018, 140 (40), 12746-12750.

(16) Kryger, M. J.; Munaretto, A. M.; Moore, J. S. StructureMechanochemical Activity Relationships for Cyclobutane Mechanophores. J. Am. Chem. Soc. 2011, 133 (46), 18992-18998.

(17) Wang, Z.; Craig, S. L. Stereochemical Effects on the Mechanochemical Scission of Furan-Maleimide Diels-Alder Adducts. Chem. Commun. 2019, 50, 2836.

(18) Stevenson, R.; De Bo, G. Controlling Reactivity by Geometry in Retro-Diels-Alder Reactions Under Tension. J. Am. Chem. Soc. 2017, 139 (46), 16768-16771.

(19) Zhang, H.; Li, X.; Lin, Y.; Gao, F.; Tang, Z.; Su, P.; Zhang, W.; Xu, Y.; Weng, W.; Boulatov, R. Multi-Modal Mechanophores Based on Cinnamate Dimers. Nat. Commun. 2017, 8 (1), 1147.

(20) Wang, J.; Kouznetsova, T. B.; Craig, S. L. Reactivity and Mechanism of a Mechanically Activated Anti-Woodward-HoffmannDePuy Reaction. J. Am. Chem. Soc. 2015, 137 (36), 11554-11557.

(21) Kean, Z. S.; Niu, Z.; Hewage, G. B.; Rheingold, A. L.; Craig, S. L. Stress-Responsive Polymers Containing Cyclobutane Core Mechanophores: Reactivity and Mechanistic Insights. 2013, 135 (36), 13598-13604.

(22) Lenhardt, J. M.; Ong, M. T.; Choe, R.; Evenhuis, C. R.; Martinez, T. J.; Craig, S. L. Trapping a Diradical Transition State by Mechanochemical Polymer Extension. Science 2010, 329 (5995), 10571060 .

(23) Lin, Y.; Barbee, M. H.; Chang, C.-C.; Craig, S. L. Regiochemical Effects on Mechanophore Activation in Bulk Materials. $J$. Am. Chem. Soc. 2018, 140 (46), 15969-15975.

(24) Kim, T. A.; Robb, M. J.; Moore, J. S.; White, S. R.; Sottos, N. R. Mechanical Reactivity of Two Different Spiropyran Mechanophores in Polydimethylsiloxane. Macromolecules 2018, 51 (22), 9177 9183.

(25) Robb, M. J.; Kim, T. A.; Halmes, A. J.; White, S. R.; Sottos, N. R.; Moore, J. S. Regioisomer-Specific Mechanochromism of Naphthopyran in Polymeric Materials. J. Am. Chem. Soc. 2016, 138 (38), $12328-12331$.

(26) Gossweiler, G. R.; Kouznetsova, T. B.; Craig, S. L. ForceRate Characterization of Two Spiropyran-Based Molecular Force Probes. J. Am. Chem. Soc. 2015, 137 (19), 6148-6151.

(27) Konda, S. S. M.; Brantley, J. N.; Varghese, B. T.; Wiggins, K. M.; Bielawski, C. W.; Makarov, D. E. Molecular Catch Bonds and the Anti-Hammond Effect in Polymer Mechanochemistry. J. Am. Chem. Soc. 2013, 135 (34), 12722-12729.

(28) Zhang, M.; De Bo, G. A Catenane as a Mechanical Protecting Group. J. Am. Chem. Soc. 2020, 142 (11), 5029-5033.

(29) Zhang, M.; De Bo, G. Mechanical Susceptibility of a Rotaxane. J. Am. Chem. Soc. 2019, 141 (40), 15879-15883.

(30) Zhang, M.; De Bo, G. Impact of a Mechanical Bond on the Activation of a Mechanophore. J. Am. Chem. Soc. 2018, 140 (40), 12724-12727. 
(31) Lin, Y.; Kouznetsova, T. B.; Craig, S. L. A Latent Mechanoacid for Time-Stamped Mechanochromism and Chemical Signaling in Polymeric Materials. J. Am. Chem. Soc. 2020, 142 (1), 99-103.

(32) Chen, Z.; Zhu, X.; Yang, J.; Mercer, J. A. M.; Burns, N. Z.; Martínez, T. J.; Xia, Y. The Cascade Unzipping of Ladderane Reveals Dynamic Effects in Mechanochemistry. Nat. Chem. 2020, 12, 302-309.

(33) Wollenhaupt, M.; Schran, C.; Krupicka, M.; Marx, D. ForceInduced Catastrophes on Energy Landscapes: Mechanochemical Manipulation of Downhill and Uphill Bifurcations Explains the RingOpening Selectivity of Cyclopropanes. ChemPhysChem 2018, 19 (7), 837-847.
(34) We have also attempted the activation a di-fluoro adduct where the $\mathrm{F}$ are meta to the scissile bond, but it was impossible to distinguish the H/D sonication products by ${ }^{19} \mathrm{~F}$ NMR. 


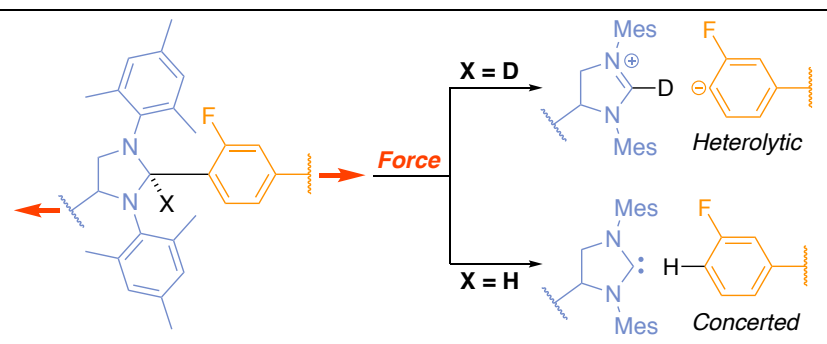

